\title{
No simple solutions
}

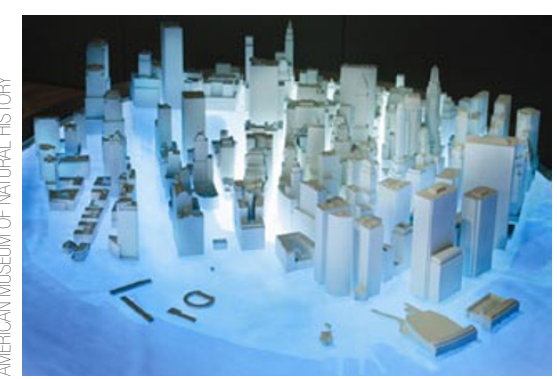

Picture this: lower Manhattan Island flooded because glacial waters from the Arctic have melted, causing sea level to rise substantially. This eerie scenario, in the form of an interactive model, is one of the first displays visitors see when entering the latest exhibition at the American Museum of Natural History, Climate Change: The Threat to Life and a New Energy Future, which opened on 18 October.

"Not to worry", we're told. "It probably would never happen", says Dr Michael Oppenheimer, professor of geosciences at Princeton University, who has organized the exhibition with Edmond Mathez, curator of Earth and Planetary Sciences at the museum. Oppenheimer is confident that, even if sea levels rose several metres - an improbable event in our lifetimes - engineers employed by the city would quickly build barriers to prevent water from inundating the city.

But we do not have to wait for Manhattan to be flooded. Make no mistake; there are many reasons for concern here and now. Human-induced climate change is already happening, with noticeable deleterious consequences. In a series of exhibits, including dioramas and videos that focus on the foibles of humans whose actions despoil the environment and waste energy, the results are stark. Take, for example, a tropical coral reef increasingly threatened as the surrounding water becomes acidic with dissolved carbon dioxide, thanks to industrialization. But there is more, as other displays show, including droughts, floods and storms, all of which could change society as we now know it.

For a museum visitor confused by global warming or unconvinced of its causes, the exhibition gives a solid introduction to the science of climate change and its effects. Wall charts showing

\section{CLIMATE CHANGE: THE THREAT TO LIFE AND A NEW ENERGY FUTURE}

American Museum of Natural History, New York.

Until 16 August, 2009.

\section{An ambitious look at how global warming is wreaking havoc with natural phenomena suggests there are no simple solutions to complex problems.}

the marked rise in atmospheric carbon dioxide over the past 400 years mention how new inventions, from the steam engine and Thomas Edison's light bulb, to today's high-tech computers, are responsible for the increases in greenhouse gas emissions. Other exhibits discuss our addiction to fossil fuels, one of the largest generators of carbon dioxide. A one-ton lump of coal occupies a central space on the exhibition floor, serving as an effective display of untapped energy.

Visitors, however, are told that all is not bleak. Remember, although we mortals can cause so much damage, we also are capable of using our ingenuity to create energy and products without, or with less, carbon dioxide emissions. But after the deluge of information on the potential catastrophic impact of climate change, it was disappointing to find only one small exhibition hall presenting possible solutions. Featured here are the obvious emerging green technologies, such as coal-burning combined with carbon capture and sequestration, being trialled effectively in Norway; solar power, the new staple industry of Silicon Valley; nuclear energy used extensively in France; thermal and hydro energy, harnessed in Iceland; and wind power, most successfully deployed in Denmark.

Scaling down to the individual are suggestions for a switch to hybrid and electric vehicles and the use of more green buildings, some with vertical gardens and even environmental walls. Clearly though we need more technical input and greater incentives to create new energy. What other new technologies are on the horizon? I, like most people, do not know, but believe that ingenuity and new technology can help to reduce greenhouse gases.

As much of the success, or lack thereof, in reducing emissions and curbing global warming will require government involvement, legislation and enlightened world leaders, it would have been appropriate to refer to this in the 'solutions' exhibition hall. Yet, the exhibition went to great lengths to encourage ordinary people to do their bit to reduce, recycle and to consider how they can make changes to protect and celebrate the environment. Though each of us must do our share, more than that is needed, however. There are several displays that ask visitors to push a button selecting how they plan to change an aspect of their behaviour. There is even a bulletin board at the end of the exhibition that gives visitors the opportunity to declare how they plan to change, now that they have seen the evil of their ways.

Yet, as most adults have heard so much of this before, the message is lost, especially after walking through several exhibition halls with the similar theme of problems caused by humankind's lack of respect for his surroundings. Perhaps the real benefactors of the exhibition will be students who need to learn about the history and effect of a society that has let unbridled growth and, in some cases, greed, damage our fragile planet. In a few years, these young people will be the new stewards of the Earth's treasures. Let's hope they take good notes and follow through in the years to come.

Following its stint in New York, the exhibition will travel to St. Louis, Cleveland and Chicago, as well as Denmark, the United Arab Emirates, Spain, South Korea and Mexico. For further information and opening hours, see the exhibition website at http://www.amnh.org/exhibitions/ climatechange.

Published online:13 November 2008

doi:10.1038/climate.2008.118

Claudia M. Caruana

Claudia M. Caruana is a New York based science and medical writer. 